\title{
Editorial
}

\section{A New Society, a "Second Precaution," and Restoration as a Strategy for Selling Ecology}

This is the first issue of R\&MN that is being sent to press as the official publication of the Society of Ecological Restoration and Management, the creation of which has just culminated in the filing of Articles of Incorporation, the scheduling of the first annual meeting (for Oakland, California, in January 1989), the mailing of a batch of fliers inviting membership, and the return of a small blizzard of replies.

All this will be of interest to readers of R\&MN partly because this is an important development-a kind of coming of age-for the discipline of ecological restoration and management generally, and also because it clearly bodes well for the journal to become and integral part of a venture of this kind.

Quite apart from improved communication through the planned newsletter, database, meetings, and so forth, the benefits for R\&MN should be substantial. Perhaps most important, the Society will place the journal at the center of a growing information exchange network, and will provide the ongoing expert advice the journal will need to grow with the discipline.

The affiliation should also help us increase circulation, a crucial step toward our goal of making the journal bigger, getting it out more frequently-in sum, of providing the restoration and management community with the space it needs for really adequate communication.

Speaking for ourselves, we can say that we welcome this initiative and are convinced that it has come about in the most favorable possible way, at the right time, and with the right kind of leadership. The organizers are all practitioners and scientists with a serious interest in the future of the discipline of restoration and management, and we are proud to find ourselves participating with them in this exciting venture.

$\mathrm{Be}$ sure to join up if you haven't already. And we'll see you in Oakland!

The creation of SERM clearly comes on the crest of a wave of growing interest in the subject of ecological restoration and management, both in the U.S. and Canada and elsewhere. One sign of this is the numerous meetings that have been held during the past year, or are scheduled for next. Glancing at our files we see notes on major meetings in Venezuela, Budapest, India and San Diego and Berkeley, California-all within about the past year.

The interest and energy that is evident here is remarkable-and encouraging. As we have indicated before, we think that restoration and management represent a flowering and maturation of environmentalism. What they offer is not a substitute for the traditional commitment to preservation (restorationists are all preservationists to begin with anyway), but something that goes beyond preservation in the narrower sense.

What we see, quite simply, is environmentalism going beyond Aldo Leopold's "first precaution"-that is, saving all the pieces-to a second precaution, which is learning to put the pieces back together again.

Significantly, of course, this second precaution is more than a precaution. It is a commitment to positive action. It is-finally - an act of faith in the possibility of a mutually beneficial relationship between ourselves and the rest of nature.

A friend recently drew our attention to The Machinery of Nature (1986, Simon and Schuster, \$18.95), Paul Ehrlich's new introduction to ecology for non-specialists. Much that is in the book is at least indirectly relevant to the business of restoration and management, of course. But what especially struck us was the epilogue, in which Ehrlich describes what he sees as the general indifference of the public to the science of ecology, and eloquently marshals the arguments for increased support for ecological research.

"The darkest cloud on the horizon of ecology at present," he writes, "is the lack of appreciation of its importance by the general public."

Ehrlich also notes the folly of overemphasizing medical research at the expense of research on the ecological systems which support all life on Earth-our own included.

"For the vast majority of human beings," he argues, "even cancer and heart disease are trivial concerns relative to those more closely related to fundamental research in ecology."'

Yet, he goes on to say, ecology is woefully underfunded-the NSF provides a mere $\$ 34$ million annually for basic ecological research, in contrast to the $\$ 4$ billion budgeted by the NIH for medical research.

Reading this, it occurred to us that there are no doubt many reasons for this general indifference, but that one of them may well be that ecology, though it has sometimes thought of itself as one of the healing arts, has rarely actually functioned in this way. Moreover, when it has, it has been preoccupied almost exclusively with the diagnosis and prognosis phases of healing, and only very rarely (and very recently, in initiatives such as restoration ecology and conservation biology) with curing systems rather than just describing what is wrong with them.

This may be worth thinking about when considering how well ecology is fulfilling its role as a healing art, and when reflecting on its claims on society's attention generally. 
The traditional emphasis on diagnosis and prognosis, which amounts to an emphasis on preventive medicine that narrower branches of medicine might well emulate, is unquestionably a strength, and one that is intrinsic to ecology with its deep sense of relationship, contingency and consequence. At the same time, it does not constitute a complete or adequate healing art.
Certainly ecology does, in principle, deserve the kind of respect-and support-that society now gives, say, the N.I.H. or the A.M.A. It will probably not achieve this, however, until ecologists are prepared, as medical doctors have been, to organize their thinking and their work around the task of caring for-and healing-the systems they work with.

William R. Jordan III

\title{
First Annual Meeting
}

\section{The Society for Ecological Restoration and Management}

\author{
January 16-20, 1989 \\ Oakland, California
}

\section{Announcement and Call for Papers}

The purpose of this meeting is to bring together researchers and managers who deal with the restoration of native ecosystems to discuss recent advances in the discipline and to present the results of current research and projects.

The three-day meeting will include concurrent paper sessions, poster sessions, a symposium on standards and evaluation methods for restoration projects, and possibly one on an aspect of restoration ecology.

Submit titles and abstracts of papers and posters to the Society's headquarters at The UW-Madison Arboretum, 1207 Seminole Highway, Madison, WI 53711 (608) 263-7889.

DEADLINE FOR SUBMISSION OF ABSTRACTS IS OCTOBER 15, 1988.
Topics: Community and ecosystem restoration, habitat creation, vegetation establishment, plant and animal reintroductions, planning and design, planting, collecting of material, soils development, site stabilization, hydrology, irrigation, equipment, administration, policy, education, and all legal, political, social, and philosophical matters pertinent to the challenge of ecological restoration.

For additional information, contact: Bill Jordan, at SERM headquarters; Donald Falk, Center for Plant Conservation, Jamaica Plain, MA (617) 524-6988; Bill Halvorson, National Park Service, Ventura, CA (805) 644-8157; or John Rieger, California Department of Transportation, San Diego (619) 237-6754. 